Contract No. and Disclaimer:

This manuscript has been authored by Savannah River Nuclear Solutions, LLC under Contract No. DE-AC09-08SR22470 with the U.S. Department of Energy. The United States Government retains and the publisher, by accepting this article for publication, acknowledges that the United States Government retains a non-exclusive, paid-up, irrevocable, worldwide license to publish or reproduce the published form of this work, or allow others to do so, for United States Government purposes. 


\title{
US PRACTICE FOR INTERIM WET STORAGE OF RRSNF
}

\author{
D.W. Vinson ${ }^{\dagger}$, R.L. Sindelar ${ }^{\dagger}$, R.W. Deible ${ }^{\ddagger}$, N.C. Iyer ${ }^{\dagger}$, and M.D. Shaffer ${ }^{\star}$ \\ †Savannah River National Laboratory, Aiken SC \\ ‡Savannah River Site, Aiken SC
}

\begin{abstract}
Aluminum research reactor spent nuclear fuel is currently being stored or is anticipated to be returned to the United States and stored at Department of Energy storage facilities at the Savannah River Site and the Idaho Nuclear Technology and Engineering Center. This paper summarizes the current practices to provide for continued safe interim wet storage in the U.S. Aluminum fuel stored in poor quality water is subject to aggressive corrosion attack and therefore water chemistry control systems are essential to maintain water quality. Fuel with minor breaches are safely stored directly in the basin. Fuel pieces and heavily damaged fuel is safely stored in isolation canisters.
\end{abstract}

\section{INTRODUCTION}

Spent fuel from research and test reactors worldwide and domestic research reactors is consolidated by the DOE at its U.S. storage sites. The foreign and domestic research reactor fuel is primarily aluminium-based, aluminium-clad, spent nuclear fuel that is being stored in wet storage in L-basin at the Savannah River Site (SRS) and in dry storage at facilities at the Idaho Nuclear Technology and Engineering Center (INTEC) at the Idaho National Laboratory. This paper provides an assessment of the current practices of the U.S. with respect to wet storage of aluminium-based research reactor fuel.

\section{DISCUSSION}

Safe management of fuel in continued wet storage involves several key functions, namely:

- Initial Condition Characterization

- Water Quality

- Water Chemistry Control System

- Corrosion Surveillance

- Isolation of Heavily Damaged Fuel

The following sections provide a discussion of the current practices for the management of spent nuclear fuel in wet storage at the Savannah River Site, highlighting the key technologies involved.

\section{Initial Condition Characterization}

Aluminum-clad nuclear fuel stored in water basins is subject to corrosion attack if the water quality and storage conditions are aggressive to aluminum. The three primary forms of corrosion observed in aluminum spent fuel when stored in low quality water include pitting corrosion i.e. localized corrosion, crevice corrosion which typically occur in crevices formed at joints, and galvanic corrosion which occur when dissimilar metals contact each other. Figure 1, shows an example of a 
fuel assembly of Materials Test Reactor design (multiple fuel plates in a "box" assembly) that has minimal corrosion attack following its use in reactor and basin storage; Figure 2 shows a fuel assembly that has undergone corrosion attack via several corrosion modes. Approximately $7 \%$ of the total number of aluminum fuel assemblies worldwide are expected to contain through-clad penetrations. ${ }^{1}$ Continued interim storage must consider this initial condition of the fuel.

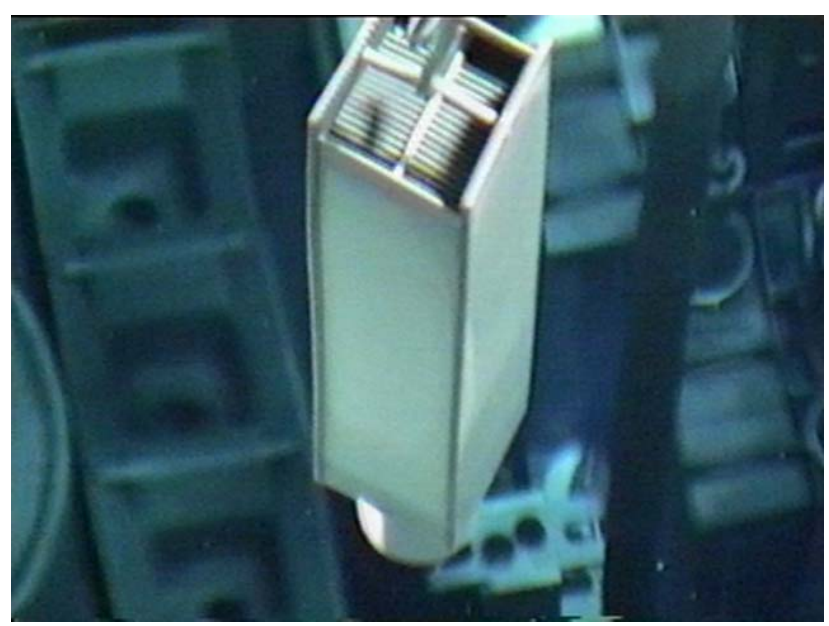

Figure 1. Aluminum-based, aluminum-clad spent nuclear (plate) fuel assembly in a good physical condition, post-irradiation and storage in a basin with good water quality.
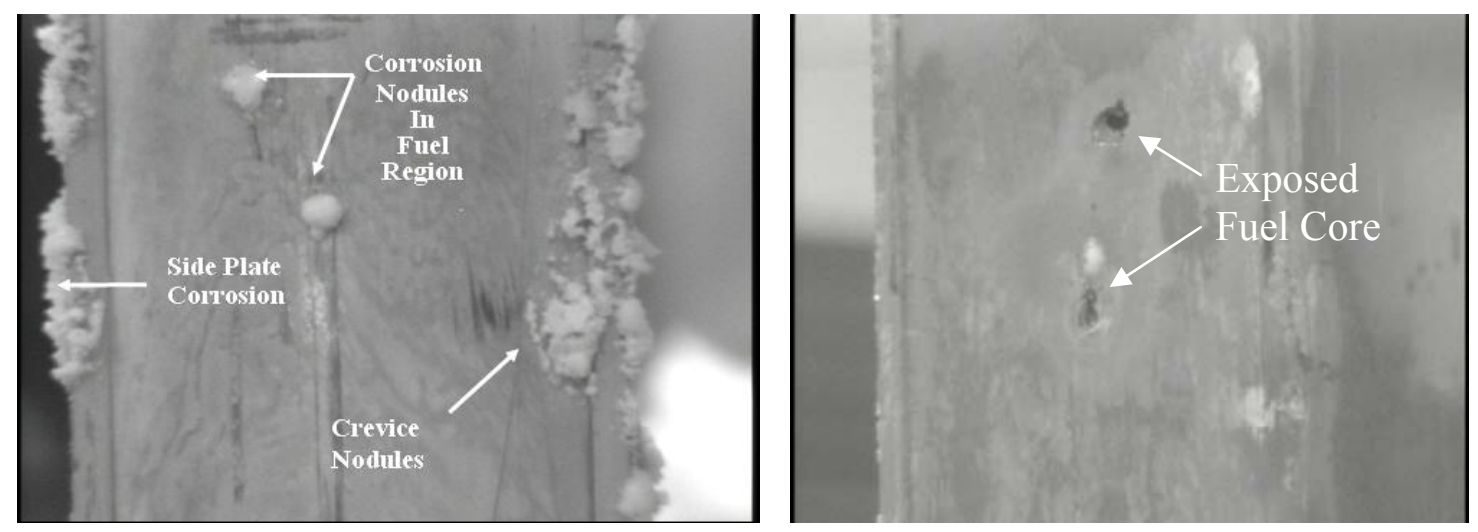

Figure 2. Aluminum-based, aluminum-clad spent nuclear fuel in moderately degraded condition post-irradiation and storage in a basin with poor water quality and storage conditions.

\section{Water Quality}

Key to the successful control of fuel corrosion in extended wet storage is effective control of the basin water quality. During the late 1960s to mid 1990s the K, C, and P reactor basins used portable deionizer systems that helped with aggressive ion and activity removal, but were far less effective than the current permanent system installed in L-basin. Through previous work and operating experience at SRS storage basins, it has been shown that the presence of aggressive 
species (i.e. chloride, nitrate, and sulfate), as well as high water conductivity, causes extensive fuel corrosion issues.

The effects of exposure to a range of aggressive ion levels were investigated in order to map the water chemistry envelope for establishment of optimal water chemistry limits. ${ }^{2}$ Cyclic polarization testing was used to perform accelerated corrosion testing on coupons of 6061 and 1100 aluminum. $\mathrm{E}_{\text {corr }}$ was measured and used to evaluate the potential impact of the water chemistry on the pitting of the material. Cyclic polarization studies were performed on A11 100 and A16061 coupons under a range of solution conditions. Results for A11100 and Al6061 were obtained at various chemistries as shown in Figures 3 and 4, respectively, indicate that the chloride ion strongly promotes corrosion of the aluminum fuel alloys.

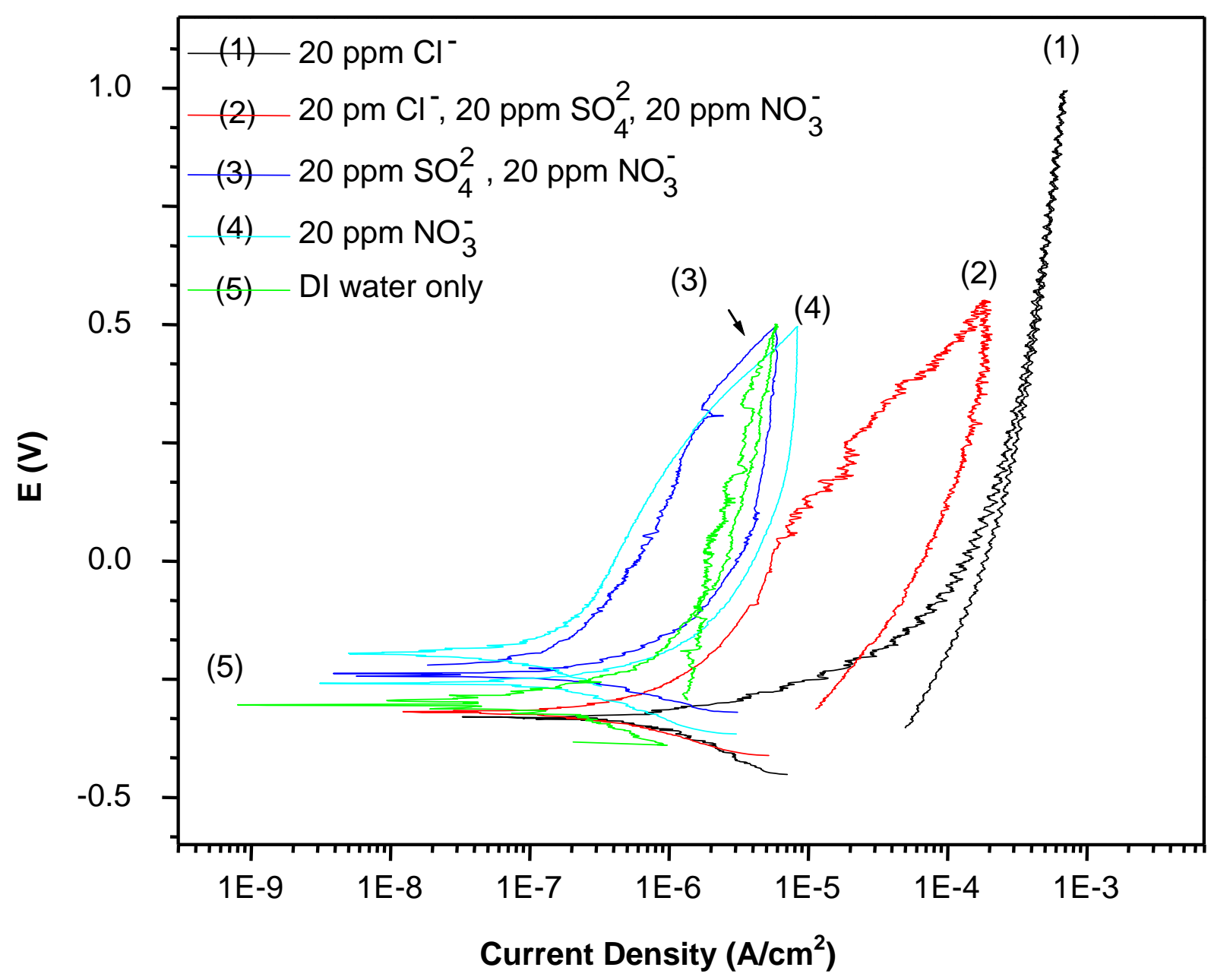

Figure 3. Cyclic polarization results from Al1 100 coupons in aggressive water chemistry. [from Reference 2] 


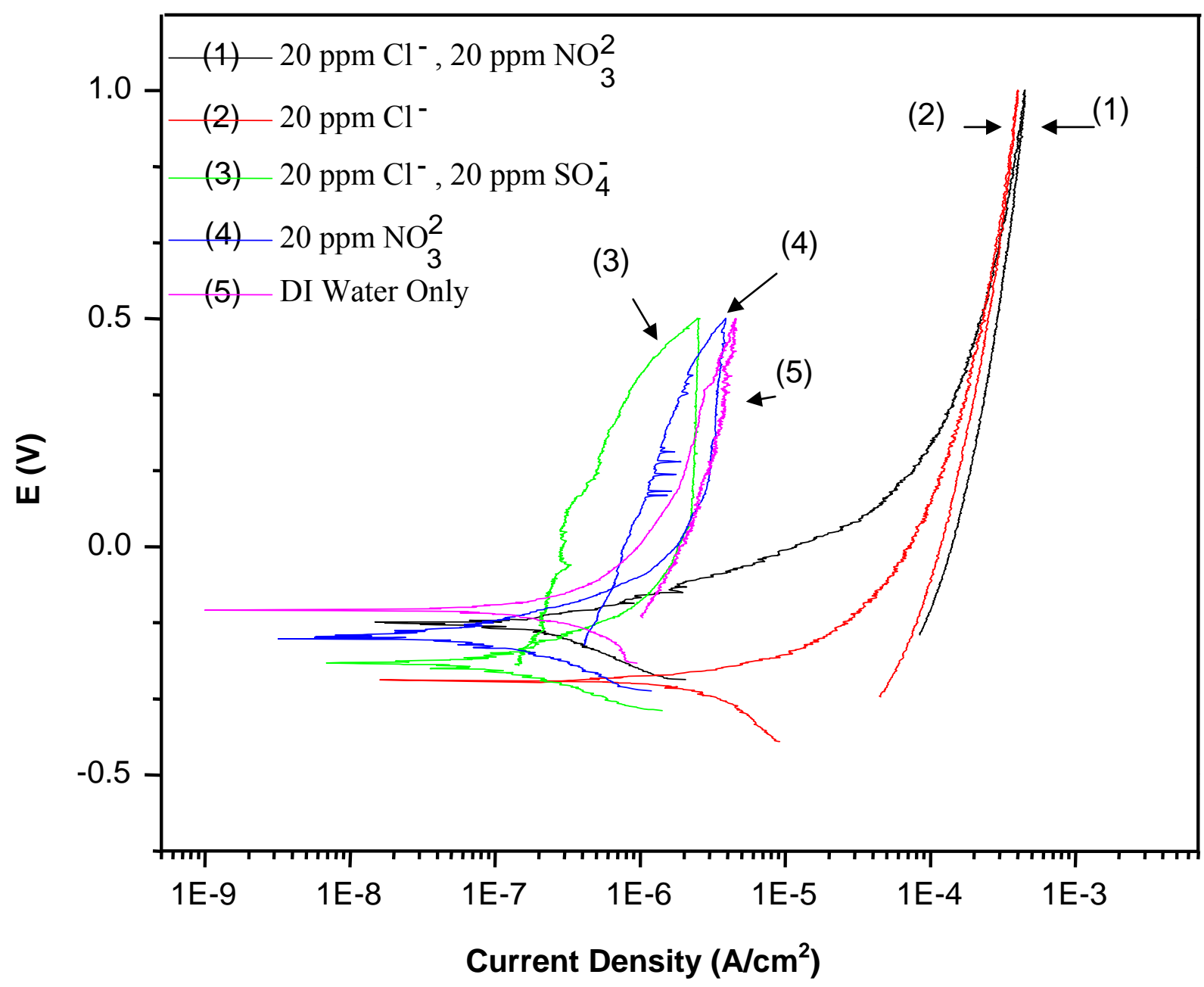

Figure 4. Cyclic polarization results from Al6061 coupons in aggressive water chemistry. [from Reference 2]

These results also indicate that while the chloride is aggressive, it may be tolerable at higher than current concentration limit of $0.1 \mathrm{mg} / \mathrm{L}$. Additionally, the data suggests that nitrate and sulfate additions have shown a tendency to inhibit pit initiation Al1100 and A16061 but further study is warranted to fully understand their effects in solution with respect to pitting and general corrosion.

The table below contains the water quality limits for aluminum fuel storage basins. A recent publication by the IAEA provides guidelines for avoiding excessive corrosion through water quality management. ${ }^{3}$ The IAEA publication on practices recommended for water quality ${ }^{3}$ includes protocols for corrosion surveillance. The purpose of a corrosion surveillance program (CSP) in a research reactor facility is to provide early detection of corrosion of components, structures and/or the nuclear fuel in contact with the water. 
Table 1. Recommended physical-chemical parameters, limits, and monitoring frequencies for water in fuel decay and storage basins [from Reference 3]

\begin{tabular}{lcc}
\hline PARAMETER & VALUE (LIMIT) & MONITORING \\
& & FREQUENCY \\
\hline $\mathrm{pH}$ & 4.5 to 7 & weekly \\
Conductivity & $<10 \mu \mathrm{S} / \mathrm{cm}$ & weekly \\
Solids & $<5 \mathrm{mg} / 1$ & Every 6 months \\
$\mathrm{Cu}$ Concentration & $<0.1 \mathrm{mg} / 1$ & Every 6 months \\
$\mathrm{Cl}$ Concentration & $<0.1 \mathrm{mg} / 1$ & Every 6 months \\
Nitrate $\left(\mathrm{NO}_{3}{ }^{-}\right), \mathrm{mg} / 1$ & $<10 \mathrm{mg} / 1$ & Every 6 months \\
Sulphate $\left(\mathrm{SO}_{4}{ }^{2-}\right), \mathrm{mg} / 1$ & $<10 \mathrm{mg} / 1$ & Every 6 months \\
Fe Concentration & $<1.0 \mathrm{mg} / 1$ & Every 6 months \\
Al Concentration & $<1.0 \mathrm{mg} / 1$ & Every 6 months \\
Temperature & $<45^{\circ} \mathrm{C}$ & monthly \\
Radioactivity level $(*)$ & $($ see note below) & Weekly \\
Turbidity $(* *)$ & (see note below) & \\
\hline
\end{tabular}

(*) Water Radioactivity level and the presence of radioisotope species should be measured each time a water sample is drawn or one time per week. A gamma scan is recommended to measure the presence of radioisotopes that would have come from failed fuel (e.g. Cs-137). No specific limits are set. The presence of radioisotope species should be evaluated on case-by-case basis. Measurement of the activity from filters and resin columns should be performed to detect the presence of leaking fuel.

$(* *)$ Turbidity should be reduced, as necessary, to provide visual clarity in the water system.

\section{Corrosion Surveillance}

The practices recommended for water quality ${ }^{3}$ includes corrosion surveillance. The purpose of a corrosion surveillance program (CSP) in a research reactor facility is to provide early detection of corrosion of components, structures and/or the nuclear fuel in contact with the water. Typically a CSP involves the exposure of a set of test coupons or rack to the basin water for a pre-determined period followed by its detailed metallurgical evaluation for corrosion. Figure 5 shows a design of a galvanic couple subset of a corrosion surveillance assembly. Figure 6 shows a photograph of an assembly following removal from the SRS L-basin.

Techniques which utilize electrochemical noise sensors have also been used to conduct corrosion surveillance, but to a much less extent. The CSP also involves the determination of water parameters at periodic intervals. The combined results from the evaluation of corrosion coupons and the water quality parameter measurements provide the basis for evaluation of corrosion on the fuel cladding and other structural materials due to exposure to the water during the time of immersion of the materials. The results also include effects of any transients in water parameters, something that often goes unperceived in the absence of a CSP. 


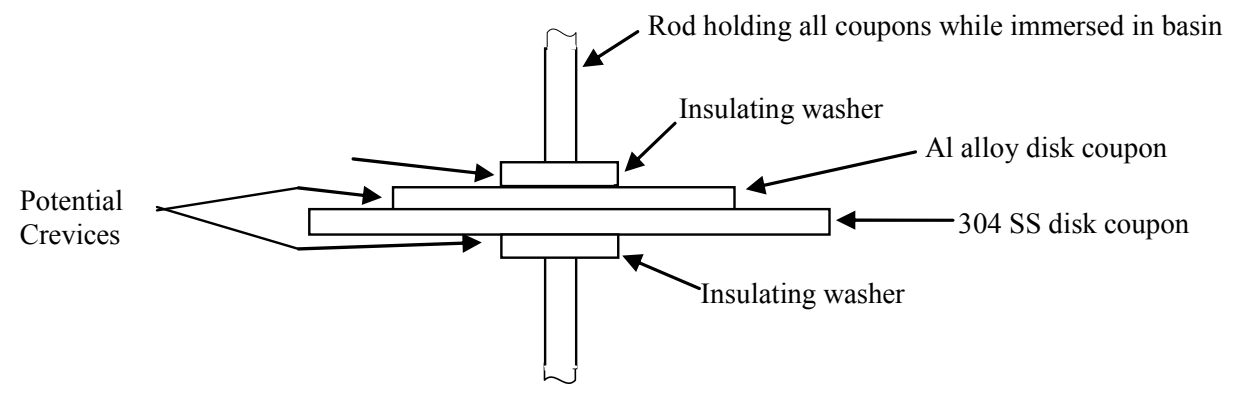

Figure 5. Schematic diagram of a galvanic coupon sub-assembly showing the crevice between the coupons and between the coupons and washers.

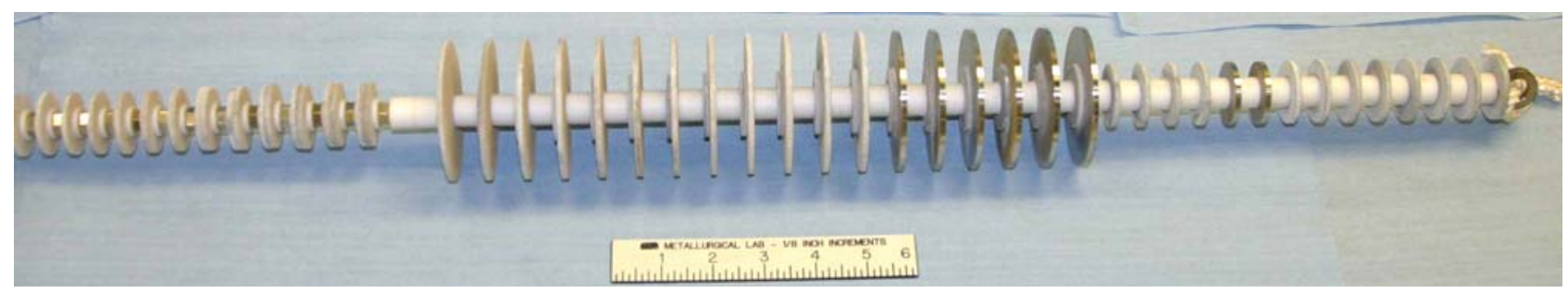

Figure 6. A coupon assembly used in a research reactor corrosion surveillance program with 32 and $70 \mathrm{~mm}$ diameter coupons. The white area between the coupons is a PTFE separator, used to isolate the central stainless steel rod from the coupon and the coupons from one another.

\section{Water Chemistry Control System}

L-basin uses zeolite and ion exchange resins for basin chemistry control for control of corrosion of the fuel. The system consists of two sand filter trains, one zeolite train, and two deionizer resin trains. The sand filter system contains sand and anthracite (coal) to remove insoluble particles. The recirculation flow through the sand filter is $1,800 \mathrm{gpm}$.

A portion of the flow (200 gpm) from the sand filter enters the zeolite and ion exchange resin systems as indicated in Figure 7. The zeolite train is a single pass, molecular sieve and ion exchange system that effectively remove cesium and strontium ions from the water after is passes through the sand filters and before it enters the anion and cation resin train. The zeolite train has two vessels which consist of $100 \mathrm{ft}^{3}$ total of zeolite.

The anion and cation train is specifically designed to minimize corrosion by removing and replacing any deleterious ions that have not been removed by the zeolite. The ion exchange resins used in the L-basin system are porous polystyrene/divinylbenzene copolymers. The resin is mostly polystyrene with some divinylbenzene cross-linking for strength.

The resins are similar except for the amount of divinylbenzene and the attached functional groups. The cation resin contains $8 \%$ divinylbenzene and the functional group is $\mathrm{SO}_{3}{ }^{-} \mathrm{H}^{+}$. The anion resin contains $4 \%$ divinylbenzene and the functional group is $\mathrm{CH}_{2}-\mathrm{N}^{+}\left(\mathrm{CH}_{3}\right)_{3} \mathrm{OH}^{-}$. 
Each of the two anion vessels contains approximately $70 \mathrm{ft}^{3}$ of resin. Each of the two cation vessels contains approximately $50 \mathrm{ft}^{3}$ of resin. The dual anion and cation train configuration provides redundancy in ion exchange capability and the resin ratio ensures both resin vessels will be spent at approximately the same time.

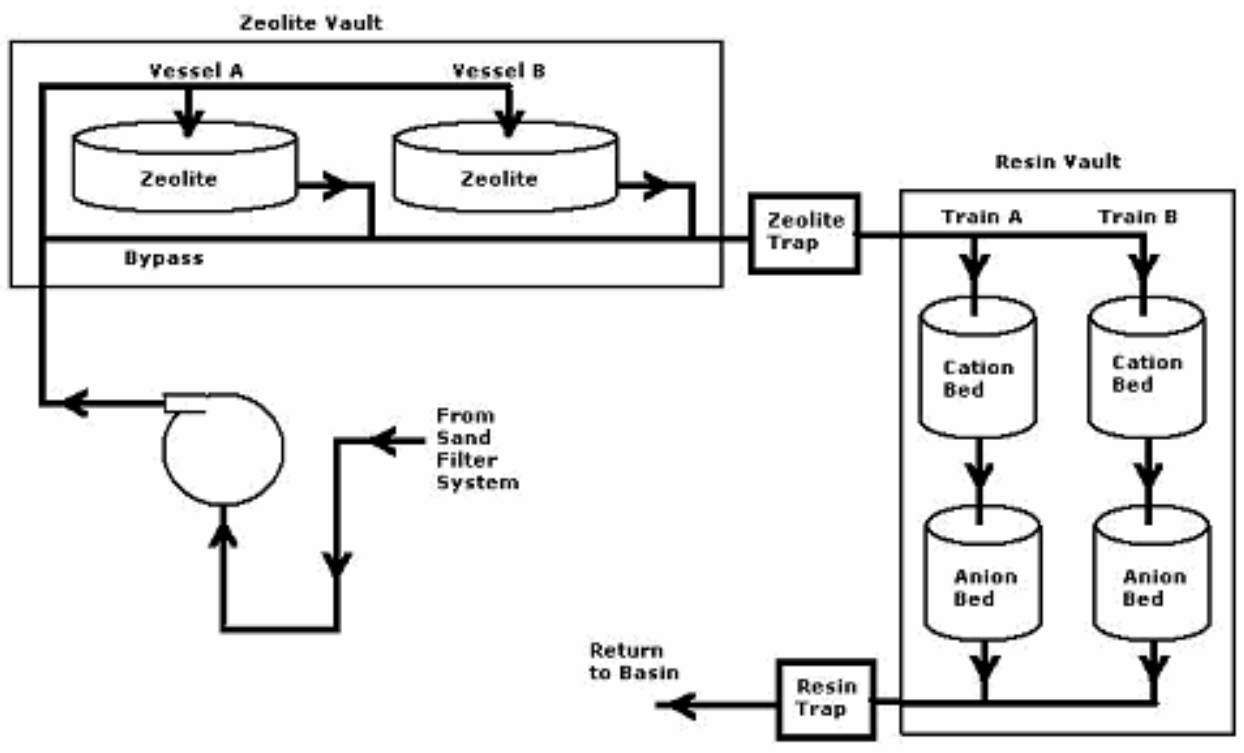

Figure 7. Water Chemistry Control System Layout for L-basin.

\section{Storage of Breached Fuel in Water Basins}

The basin activity is dominated by the concentration of ${ }^{137} \mathrm{Cs}$ in the basin water as determined by chemical analysis of basin water samples. Therefore, modeling release rates from Al-SNF into the basin water concentrates on the release rate of ${ }^{137} \mathrm{Cs}$. In general, the release of radioactivity from Al-SNF with breached cladding into water is dependent on several factors:

- area of exposed fuel

- environment (temperature and quality of the water);

- radioisotope content of fuel (enrichment, burn-up, and decay time);

- fuel meat material (post-irradiation composition and microstructure); and

- clad material

At the low temperatures typical of basin storage (approximately room temperature), corrosion is the primary mechanism whereby species from the fuel core are released into the water. That is, diffusion transport of species from regions in the fuel core to the exposed fuel surface and direct release is not significant.

The radionuclides are assumed to be fully soluble and free to disperse into the water, and not bound in the corrosion product. A simple model to estimate the release from fuel core has been developed 
by considering general corrosion of the fuel core region directly exposed to the environment. ${ }^{4}$ The release model is given by:

$$
\mathrm{R}=\mathrm{A} \times \mathrm{B} \times \mathrm{C}
$$

where:

$\mathrm{R} \quad$ is the ${ }^{137} \mathrm{Cs}$ release rate $[\mathrm{Ci} / \mathrm{hr}]$;

A is the ${ }^{137} \mathrm{Cs}$ activity density in the fuel meat material at the decay time of interest $\left[\mathrm{Ci} / \mathrm{cm}^{3}\right]$;

$\mathrm{B} \quad$ is the area of fuel exposed to the environment (area of breach) $\left[\mathrm{cm}^{2}\right]$; and

$\mathrm{C}$ is the general corrosion rate of the fuel core material in the environment of exposure $[\mathrm{cm} / \mathrm{hr}]$.

\section{Steady-State Release into the Basin}

The impurity specie will ultimately reach a steady-state concentration in a basin that has a constant source of impurity specie addition, or release rate, into the water with an online deionization system for the basin. That is, at $\mathrm{t}=$ infinity, the concentration of an impurity specie $\mathrm{C}(\mathrm{t})=\mathrm{C}_{\mathrm{SS}}$. For a closed loop system the steady-state concentration of radioactivity in the water, $\mathrm{C}$ (in $\mathrm{Bq} / \mathrm{L}$ ), is given by (2):

$$
\mathrm{C}_{\mathrm{SS}}=\mathrm{R} /(\mathrm{Q} \varepsilon)
$$

Where $\mathrm{Q}$ is the volumetric flow rate in $\mathrm{L} / \mathrm{s}$ into and out of a closed loop deionization system, $\mathrm{R}$ is the total release rate of radioactivity into the water in $\mathrm{Bq} / \mathrm{s}, \varepsilon$ is the efficiency of the deionizer system and $\mathrm{C}_{\mathrm{SS}}$ is the activity of the water in $\mathrm{Bq} / \mathrm{L}$ at steady-state.

Once again, this method can be applied to any specie of interest in a reactor water system, recalling that the efficiency of most deionization systems is $100 \%(\varepsilon=1)$ until the resin has reached its capacity.

\section{Mitigating Severely Breached Fuel in Wet Storage}

The DOE complex has a long history of handling a wide variety of damaged fuel types. Placing a damaged fuel assembly in an isolation canister has been a common solution to contain radioactive isotopes that can be released from breached-cladding (primarily Cs-137). Experience has shown that isolation canisters with special design features are effective in isolating breached or damaged SNF from the bulk basin water.

Isolation canisters for damaged SNF are designed to allow underwater storage of the highly damaged fuel while sequestering the radionuclides that is released from it. Containing the released radioactive material is important from the standpoint of radiological protection of basin operations personnel and waste reduction realized from lower frequency of regeneration/replenishment of basin deionizer resin beds. A common design feature in the early SRS-design isolation canisters was a J-tube in the lid of the canister. (Figure 8) The J-tube acts in combination with evolved gas within the oversized containers to separate the internal water environment from bulk basin water. Gases released from damaged SNF build up at the top of the can and into the J-tube. Figure 9 shows a schematic of the new lid design that incorporates the inverted J-tube. The improved design of the inverted J-tube isolation canisters were developed to mitigate problems with pluggage due to 
silt buildup within the early J-tubes. ${ }^{5}$ In employing isolation canisters for the storage of damaged/degraded spent nuclear fuel, the canister provides the necessary and critical design features that were once performed by the fuel structure and cladding.

Historically, SRS chose isolated storage in water for the significantly damaged and destructively tested fuel, separating it from the remainder of the basin water by loading it into large water-filled canisters. The method of storing damaged fuel underwater was to place fuel pieces in small diameter canisters (some aluminum and some stainless steel) which were grouped with others and placed in larger aluminum vessels referred to as over-sized (OS) canisters (Figure 8).

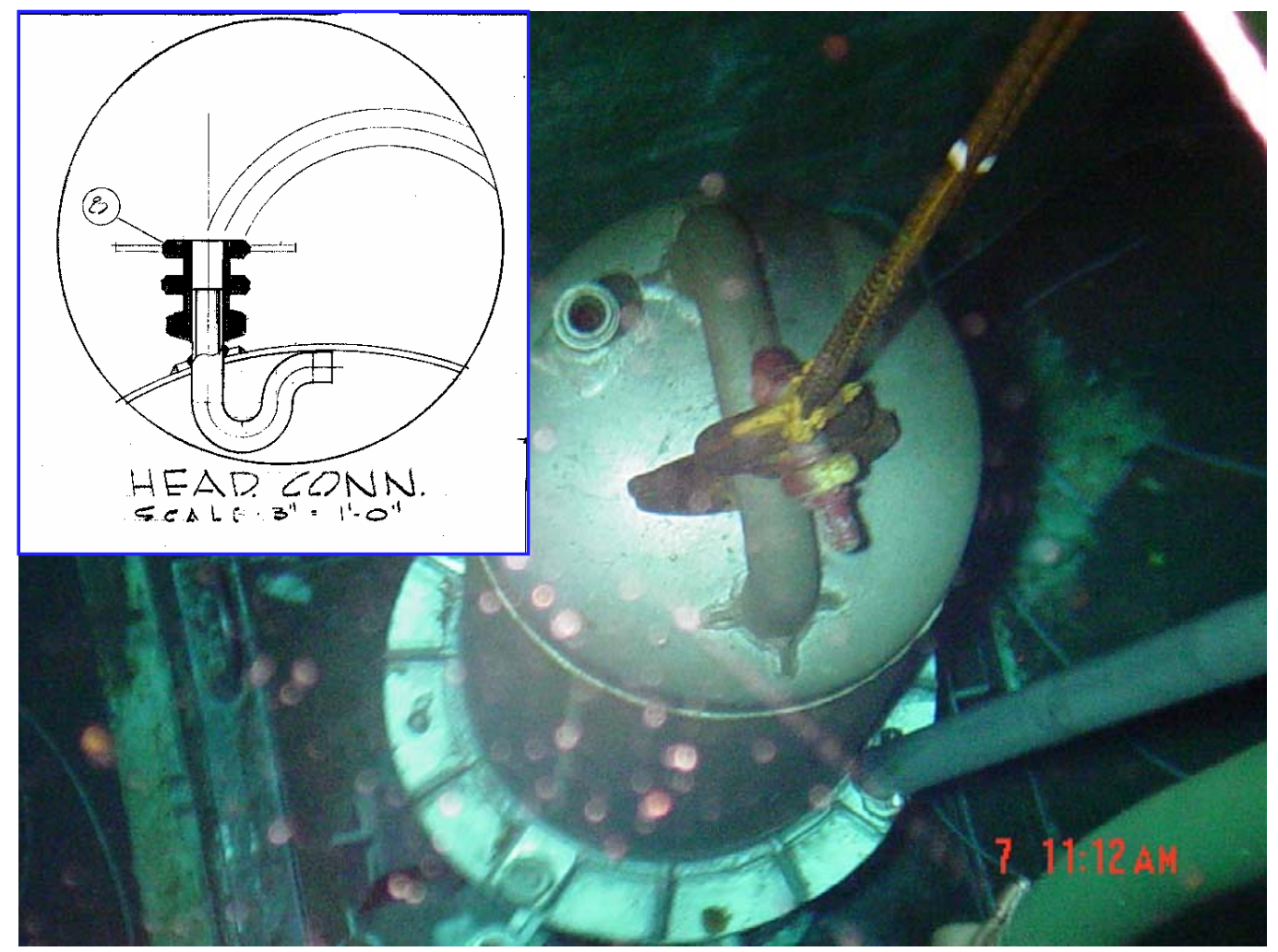

Figure 8. Schematic illustration of a J-tube common to early SRS isolation canisters.

The SRS experience with these oversized isolation canisters illustrates the benefit and the potential liability with the employment of isolation canister technology. The isolation canister effectively isolates the bulk basin water from the water within the isolation canister. However, the water within the isolation canister may become increasingly more contaminated with fission products from the ongoing fuel degradation process. This becomes significant if there comes a need to open the isolation canister as in the case of the SRS oversized isolation canisters. This need arose during the deinventory activities at the SRS Receiving Basin for Offsite Fuels (RBOF). To remove locally the highly contaminated water and minimize the impact on the bulk basin water activity upon opening the OS canisters, SRS developed and deployed a system to clean the water within the isolation canister through a submersible filtration and deionization system. 


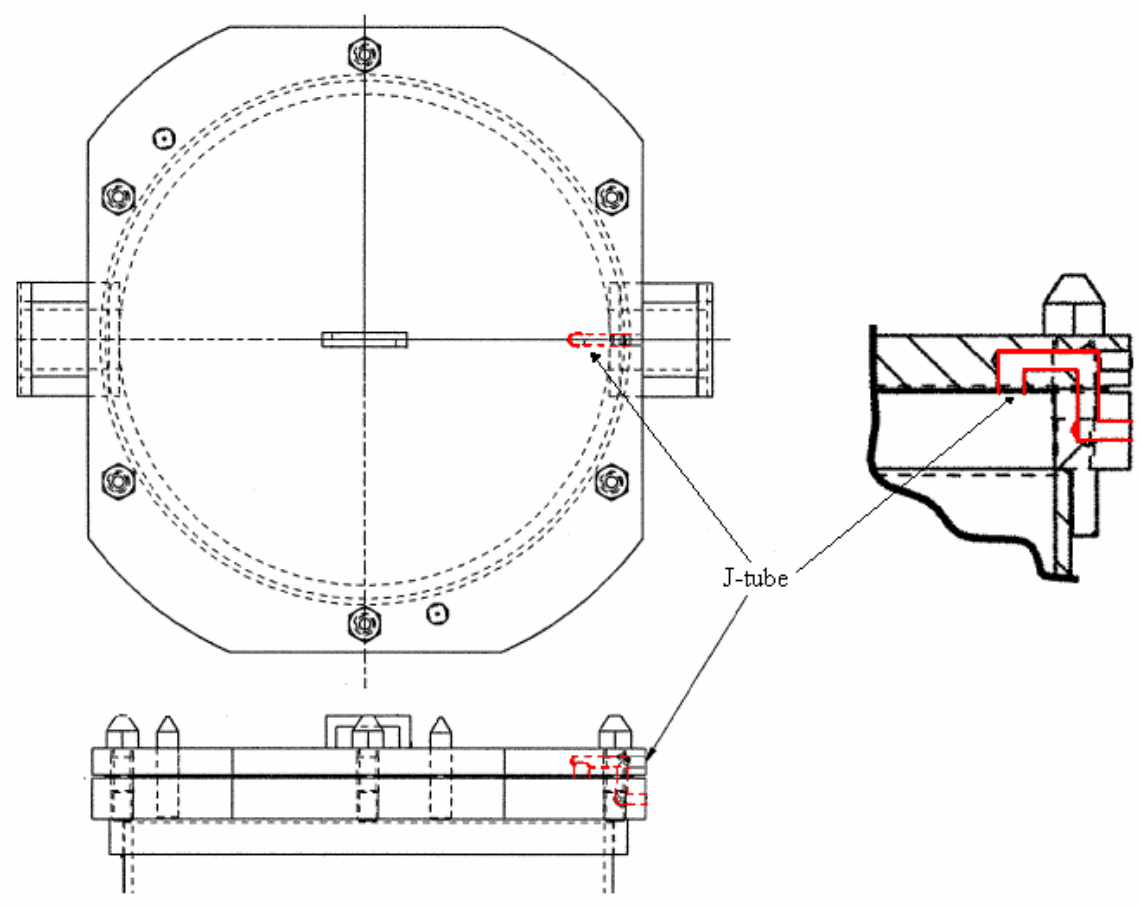

Figure 9. Later inverted J-tube design on damaged-fuel storage can.

\section{Underwater Deionizer}

The required parts of the underwater deionizer in its simplest form were: a pump and motor, filter, and an ion-exchange column (Figure 10). The system footprint was minimized to maximize flexibility and mobility of the deionizer system. The system was uniquely designed with the appropriate amount of cation resin to ensure maximum ion exchange efficiency. Positive displacement, water-lubricated gear pumps (redundant) were powered by non-lubricated air motors, allowing variable speed operation and protection against locked-rotor situations. The design was checked for code compliance, fabricated, and fully tested before delivery to RBOF.

The redundant pumps and their corresponding motors were fixed to a $0.71 \times 0.91 \mathrm{~m}$ skid and plumbed together with stainless steel pipe, having a common suction from the filter. Each pump was followed by a check valve before joining to a common flow meter. The check valves allowed either pump to operate singly, without recirculating water to the suction, or simultaneously, if desired. Figure 11 shows the underwater deionizer as it was positioned in the SRS RBOF basin, 4.6 $\mathrm{m}$ below the surface of the water. The site personnel planned and performed, OS canister flushing using the submersible deionizer with excellent results. During the operation, dose rates in the general basin water were maintained below the limit of $0.02 \mathrm{mGy} / \mathrm{hr}$. The deionizer removed radioactive material from OS canister water allowing damaged fuel to be moved into more modern storage containers with the improved inverted J-tube and designed to fit the racks in the destination facility. 


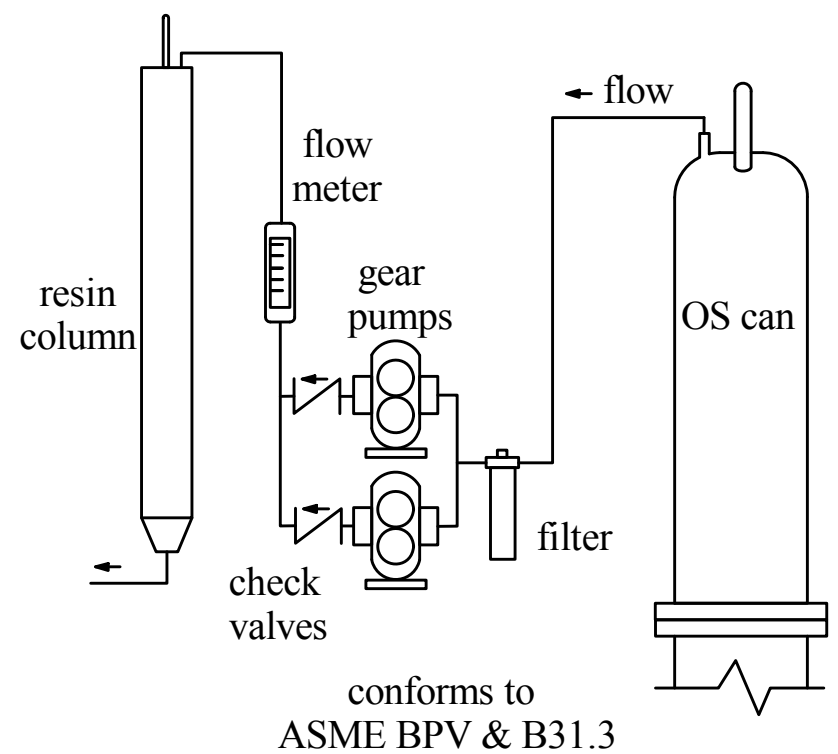

Figure 10. RBOF underwater deionizer sketch.

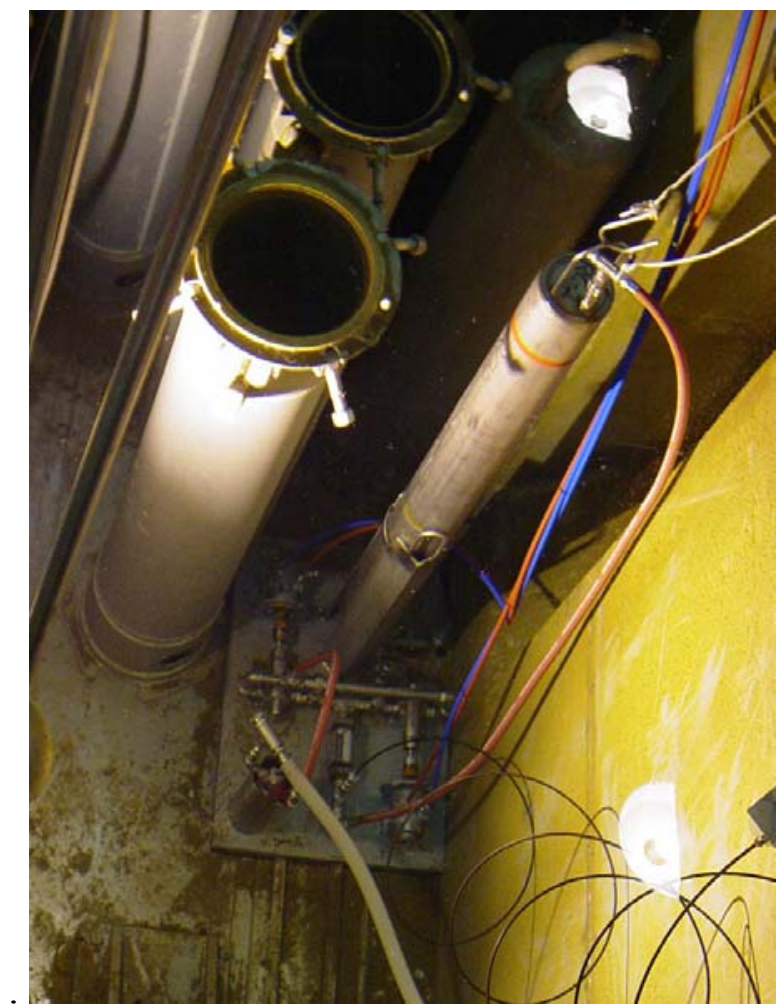

Figure 11. RBOF underwater deionizer with empty oversized canister halves. 


\section{CONCLUSIONS}

The aluminum fuel storage experience to date in the U.S., supported by the understanding of the effects of environmental variables on materials performance, demonstrates that storage systems that minimize degradation and provide full retrievability of the fuel up to several decades can be achieved in wet storage facilities. Continued surveillance and evaluation of the fuel and storage system materials to verify the predicted impact of the environment on materials behavior remains paramount to ensure reliable safe storage throughout the storage period.

\section{REFERENCES}

1 H.M. Brooks and R.L. Sindelar. "Characterization of FRR SNF in Basin and Dry Storage Systems," in Proceedings of the Third Topical Meeting on DOE Spent Nuclear Fuel and Fissile Materials Management, Charleston, SC (September 8-11, 1998).

2 D.J. Hathcock, T.R. Murphy, P.R. Vormelker, S.P. Harris, and R.W. Deible, "Spent Nuclear Fuel Storage Basin Water Chemistry: Electrochemical Evaluation of Aluminum Corrosion," NACE Corrosion 2008.

3 Recommended practices for water quality management in research reactors \& spent fuel storage facilities, IAEA Nuclear Energy Series, to be published 2010.

4 R.L. Sindelar and J.P. Howell, "Radioactivity Release from Aluminum-Based Spent Nuclear Fuel in Basin Storage (U)," WSRC-TR-97-0153 (May 1997).

5 B. Carlsen, D. Fillmore, E. Woolstenhulme, R.L. McCormack, R.L. Sindelar, T.J. Spieker, "Experience With Damaged Spent Nuclear Fuel at U.S. DOE Facilities," ICONE 14-89319, July 1, 2006, OSTI ID: 20995511. 